\title{
() . \\ ANÁLISE DE IMPACTO ORÇAMENTÁRIO (BIA) DA DOR CRÔNICA SOB A PERSPECTIVA DE UMA AUTOGESTÃO
}

\section{João Paulo dos Reis Neto' e Juliana Martinho Busch ${ }^{2}$}

1Diretor-Presidente, ${ }^{2}$ Diretora de Previdência e Assistência

CAPESESP - Caixa de Previdência e Assistência dos Servidores da Fundação Nacional de Saúde, Brasil

\section{INTRODUÇÃO}

Um estudo multicêntrico realizado em 1998 pela Organização Mundial de Saúde (OMS) mostrava a prevalência de dor crônica em $22 \%$ da população (1), sendo considerada um grande problema de saúde, com diferentes taxas de prevalência (30\% a 50\%). No Brasil, afeta cerca de $30 \%$ dos adultos, que consomem mais recursos da saúde que a população geral $(2,3)$.

\section{OBJETIVO}

Este estudo analisa o impacto econômico da dor crônica em beneficiários de um plano de saúde.

\section{RESULTADOS}

Da amostra, 20,6\% relataram dor há mais de 30 dias (média de 53,4 anos, $60,1 \%$ do sexo feminino, $39,9 \%$ do sexo masculino). Destes $43,9 \%$ relataram dor na coluna, $16,2 \%$ dor no membro inferior, $14,9 \%$ cefaléia, $9,6 \%$ dor abdominal, $8,1 \%$ dor no membro superior e $7,3 \%$ em outras regiões. No grupo de beneficiários que informaram a presença de dor, a utilização do plano de saúde foi significativamente maior para consultas $(p=0,004$, OR 4,66) e exames $(p<0,001$; OR 4,73), e não significativa para terapias ( $p=0,352$, OR 4,85$)$ e hospitalizações ( $p=0,652$, OR 4,09). A despesa anual foi de $R \$ 5.400,97$ versus $R \$ 4.866,19$ em pacientes que não referiram dor ( $p<0,001$; OR 4,29).

Considerando a prevalência e o custo incremental, o impacto anual estimado da dor crônica na operadora foi de $R \$ 7.332 .235,34$
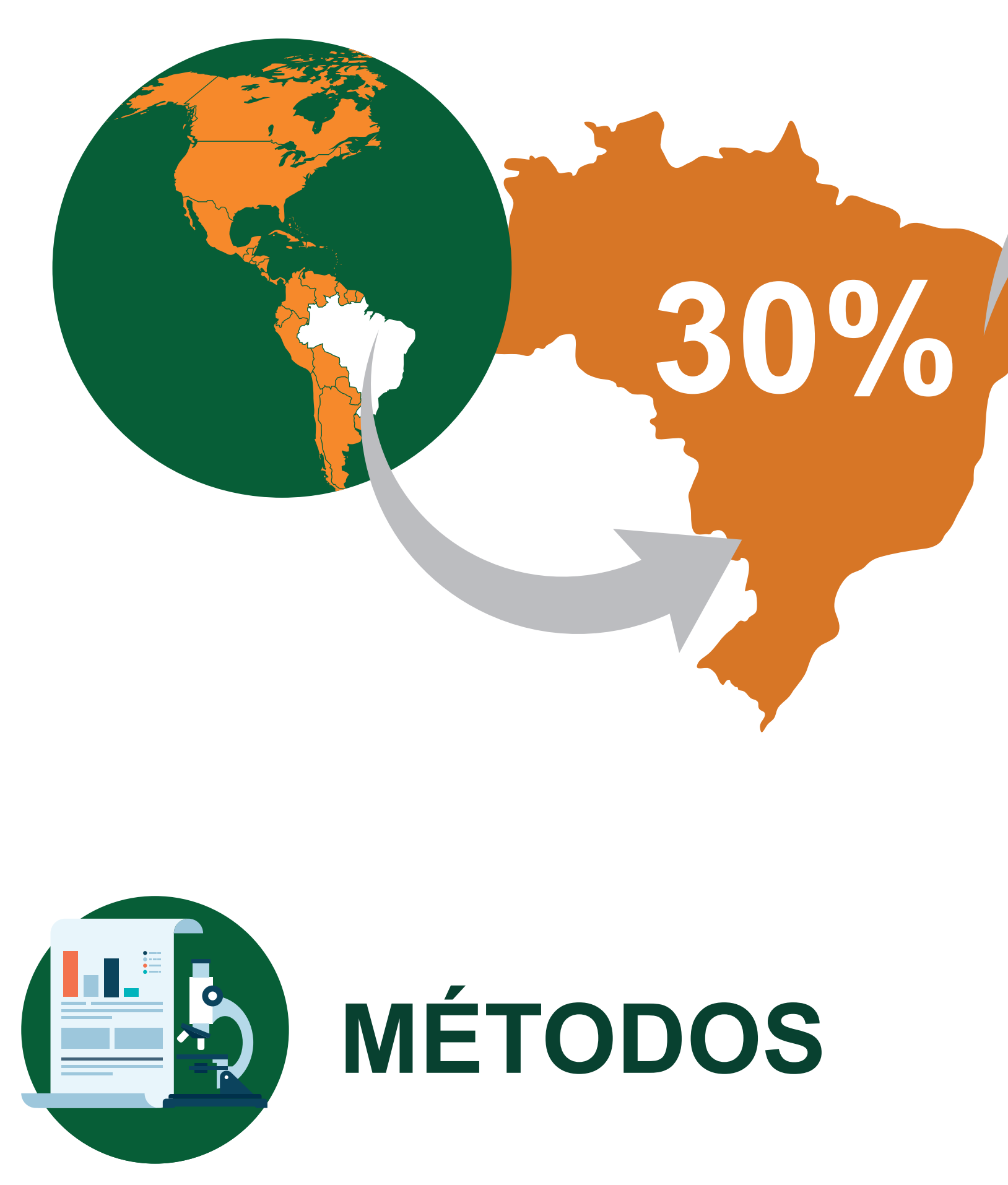

\section{MÉTODOS}

Foi realizada pesquisa online de morbidade referida em 97.983 beneficiários, de onde extraímos uma amostra de 2.188 indivíduos que responderam a perguntas categóricas sobre a presença de dor sem razão aparente. Nos casos afirmativos investigamos a duração da dor e o uso de terapias de alívio. A utilização do plano de saúde e os custos anuais envolvidos foram analisados e comparados com aqueles de indivíduos que não relataram dor. A análise estatística utilizou o software OpenEpi, calculando as frequências relativas e absolutas, médias e desvio padrão. Para significância estatística, os testes Qui-quadrado (Mantel-Haenszel e Exato de Fisher), quando $p<0,005$.

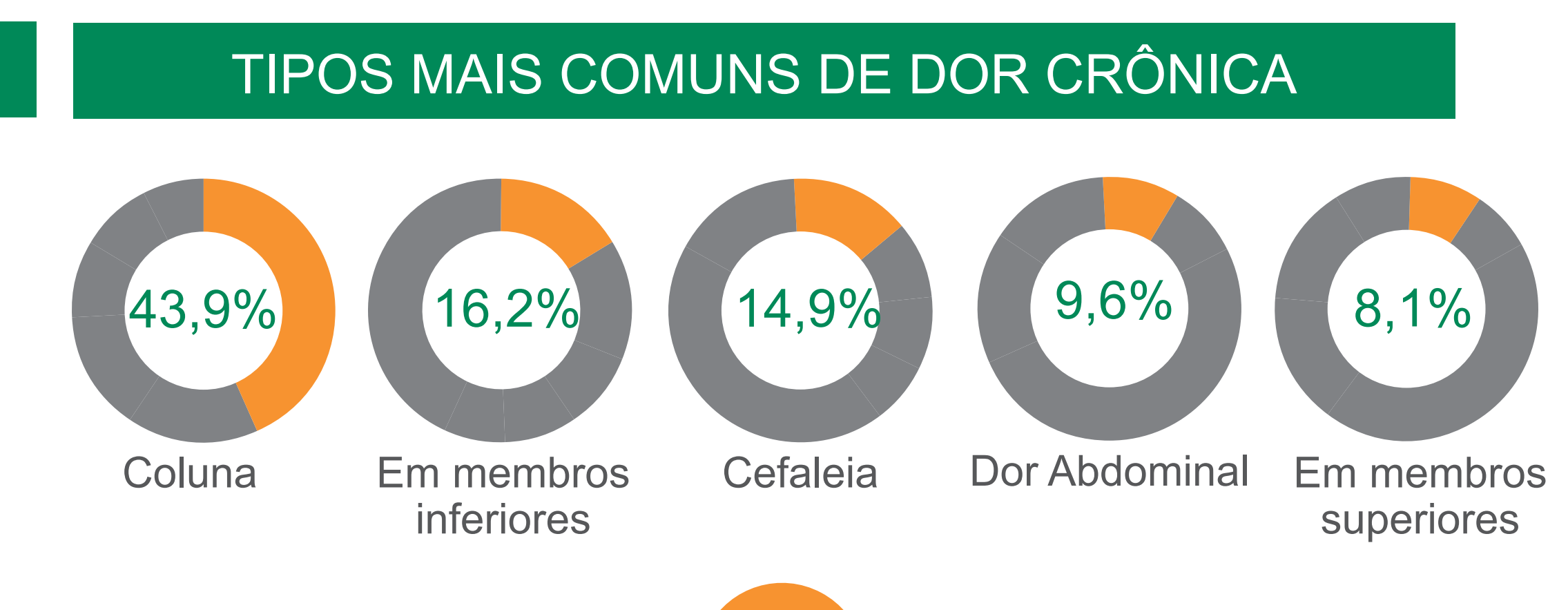

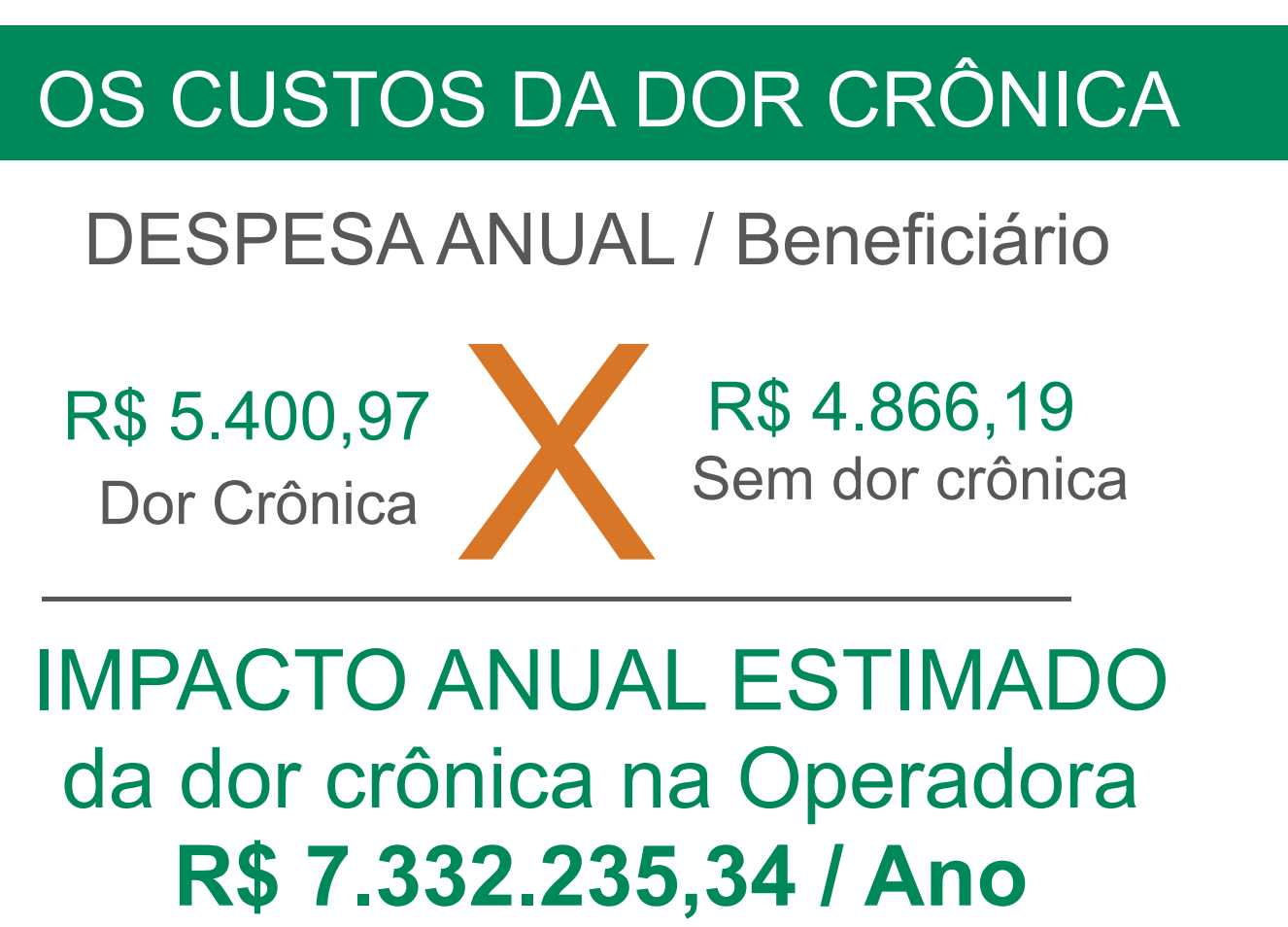

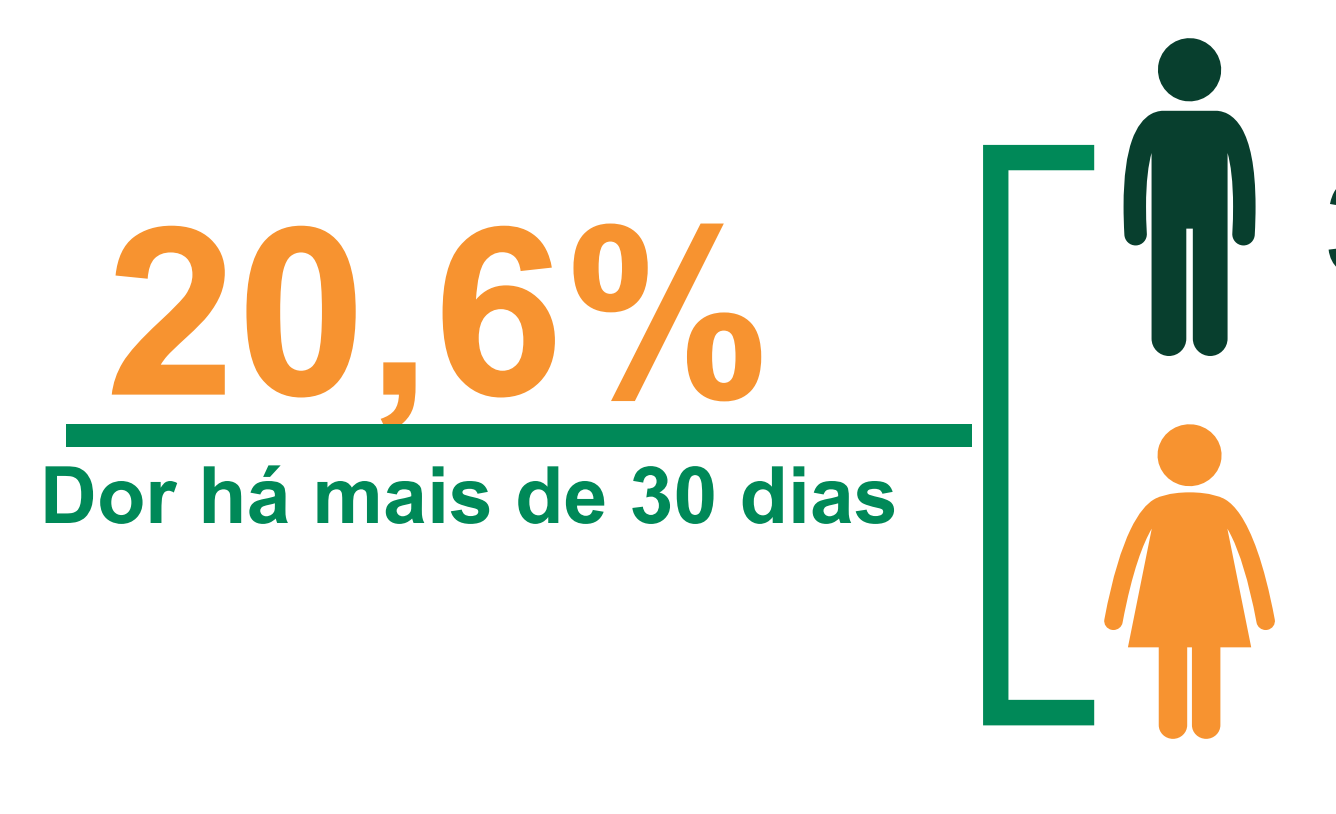

\section{CONCLUSÕES}

Quando comparado ao custo anual de beneficiários com outros problemas de saúde, a dor crônica resulta em um custo incremental significativo devido a maior utilização do plano, concentrados especialmente nos eventos ambulatoriais. Outros aspectos a serem considerados, descritos na literatura, são os impactos a longo prazo sobre a qualidade de vida do paciente e seus familiares.

\section{REFERÊNCIAS BIBLIOGRÁFICAS}

1. Fayaz A, Croft P, Langford RM, et al Prevalence of chronic pain in the UK: a systematic review and meta-analysis of population studies BMJ Open 2016;6:e010364. doi: 10.1136/bmjopen-2015-010364

2. Souza JB, Grossmann E, Perissinotti Navas DM, Oliveira Junior JO, Fonseca Barreiros PR and Posso IP, "Prevalence of Chronic Pain, Treatments, Perception, and Interference on Life Activities:

Brazilian Population-Based Survey," Pain Research and Management, vol. 2017, Article ID 4643830, 9 pages, 2017

Sullivan W. et al. Economic Evaluation in Chronic Pain: A Systematic Review and de Novo Flexible Economic Model. The European Journal of Health Economics 17 (2016): 755-770. PMC. Web. 6 Oct. 2018.

. Breivik $H$, Collett B, Ventafridda V, Cohen $R$, Gallacher D, Survey of chronic pain in Europe: Prevalence, impact on daily life, and treatment, European Journal of Pain, Volume 10, Issue 4,2006, Pages 287-333

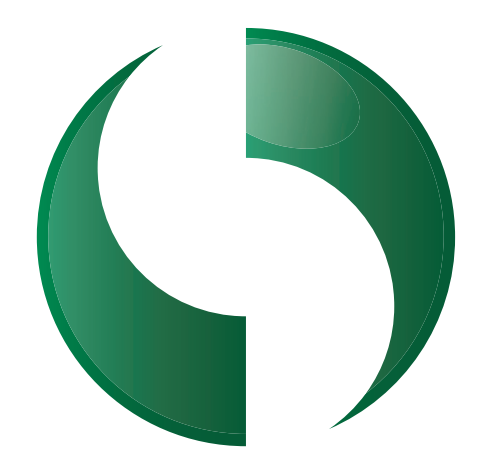

CAPESESP

www.capesesp.com.br

(f) (100)

/capesespoficial 